\title{
EDUCAÇÃO SANITÁRIA NO ESTADO DE SÃO PAULO, BRASIL: CONCEPÇÕES DIFUNDIDAS ENTRE 1917 E 1967*
}

\author{
Health education in the State of São Paulo, Brazil: conceptions \\ spread between 1917 and 1967
}
Educación sanitaria en el Estado de São Paulo, Brasil: concepciones difundidas entre 1917 y 1967

\section{Maria Cristina da Costa Marques, ${ }^{\alpha}$ Danilo Fernandes Brasileiro ${ }^{\beta}$ e João de Oliveira Gusmãox}

Data de aceitação: 05/04/2021 • Data de receção: 08/09/2021

Resumo. O período de 1917 a 1967 foi peculiar na história da saúde pública paulista, no Brasil, sobretudo na implementação e consolidação de medidas voltadas à intervenção individual e coletiva, sustentadas por um conjunto de normas, apoiadas por regras higiênicas de mudança de hábitos de vida, viabilizadas através de inúmeras estratégias de educação sanitária. Pretende-se com o presente estudo, identificar as concepções de educação sanitária que sustentaram a prática de educação sanitária entre os anos de 1917 e 1967, no Estado de São Paulo. Trata-se, portanto, de uma revisão de escopo da literatura científica, que com buscas em bases de dados digitais, selecionou previamente 214 artigos, que submetidos a análise mais apurada, permitiu incluir 14 artigos no corpus documental do estudo. Dos 14 artigos selecionados, a maior parte deles produzidas por pesquisadores paulistas, com intervalo temporal de

\footnotetext{
" Trabalho extraído da pesquisa Fapesp (Processo n ${ }^{\circ}$ 2019/10699-8): Transformações na formação do especialista em Saúde Pública pela Faculdade de Saúde Pública da Universidade de São Paulo entre 1928 a 2008.

a Professora doutora da Faculdade de Saúde Pública da Universidade de São Paulo. Brasil. mcmarques@usp.br (D) http://orcid.org/0000-0002-7461-3710.

$\beta$ Mestre em Ciências e doutorando da Faculdade de Saúde Pública da Universidade de São Paulo. Brasil. danilo.brasileiro@hc.fm.usp.br (D) http://orcid.org/0000-0002-3905-7579.

× Aluno de graduação da Faculdade de Saúde Pública da Universidade de São Paulo. joaogusmao@ usp.br (D) https://orcid.org/0000-0003-0845-3621.
}

Como citar este artigo: Da Costa Marques, Maria Cristina, Fernandes Brasileiro, Danilo y De Oliveira Gusmão, João. «Educação sanitária no Estado de São Paulo, Brasil: concepções difundidas entre 1917 e 1967». Historia y Memoria de la Educación 15 (2022): 203-228 
1936 desde a publicação do primeiro, até 2018, quando se publicou o último artigo. Encontrou-se duas categorias de análise que refletiram as concepções que sustentaram a prática da educação sanitária no Estado de São Paulo: (1) Educação Sanitária como Expressão da Biopolítica e (2) Educação Sanitária como Expressão da Eugenia. Concluiu, portanto, que o Estado de São Paulo, utilizou da educação sanitária como aliado para atingir seus objetivos de construção de um projeto de modernidade, sendo a eugenia e biopolítica as expressões mais contumazes desse processo.

Palavras-chave: História; Saúde Pública; Educação Sanitária; Eugenia; Biopolítica.

Abstract. The period from 1917 to 1967 was peculiar in the history of public health in São Paulo, Brazil, especially regarding the implementation and consolidation of measures aimed at individual and collective interventions supported by a set of norms and by hygienic rules for changing lifestyle habits, all made possible by numerous health education strategies. This study intends to identify the conceptions of health education that guided the practice of health education between the years 1917 to 1967, in the State of São Paulo. It consists of a review of the scientific literature, consulted in digital databases, from which 214 previously selected articles from a rapid analysis led us to choose 14 articles for the documentary corpus of the study. Most of the 14 selected articles were produced by researchers from São Paulo between 1936 and 2018, when the last article was published. We discovered two categories of analysis that reflect the concepts that underpinned the practice of health education in the State of São Paulo: (1) Health education as an Expression of Biopolitics and (2) Health education as an Expression of Eugenics. We conclude, therefore, that the State of São Paulo used health education as an ally to achieve its goals of building a project of modernity, leading to eugenics and biopolitics as the most compelling expressions of this process.

Keywords: History; Public health; Health education; Eugenics; Biopolitics.

Resumen. El período de 1917 a 1967 fue peculiar de la historia de la salud pública en São Paulo, en Brasil, principalmente por la implementación y consolidación de medidas dirigidas a la intervención individual y colectiva, sustentadas en un conjunto de normas, respaldado por reglas higiénicas para cambiar los hábitos de vida, posible gracias a numerosas estrategias de educación sanitaria. El objetivo de este estudio es identificar los conceptos de educación sanitaria que apoyaron la práctica de la educación para la salud entre los años 1917 y 1967, en el Estado de São Paulo. Se trata, por tanto, de una revisión del alcance de la literatura científica que, con búsquedas en bases de datos digitales, previamente seleccionados 214 artículos que, 
sometidos a un análisis más preciso, permitió incluir 14 artículos en el corpus documental del estudio. De los 14 artículos seleccionados, la mayoría fueron producidos por investigadores de São Paulo, con un intervalo de tiempo de 1936 desde la publicación del primero, hasta 2018, cuando se publicó el último. Se encontraron dos categorías de análisis que reflejaron los conceptos que sustentaron la práctica de la educación sanitaria en el Estado de São Paulo: (1) Educación sanitaria como expresión de la biopolitica y (2) Educación sanitaria como expresión de la Eugenesia. Concluyó, por tanto, que el Estado de São Paulo utilizó la educación sanitaria como un aliado para lograr sus objetivos de construir un proyecto moderno, siendo la eugenesia y la biopolítica las expresiones más llamativas de este proceso. Palabras clave: Historia; Salud pública; Educación sanitaria; Eugenesia; Biopolítica.

\section{INTRODUÇÃO}

O presente artigo, por meio de uma revisão de escopo da literatura, dedicou-se a analisar a experiência do estado brasileiro de São Paulo, entre os anos de 1917 e 1967, período de mudanças importantes no paradigma de Saúde Pública e de regulamentação em saúde, com o objetivo de identificar as concepções de educação sanitária presentes no período e conseqüentemente compreender quais foram as influências ideológicas, políticas e científicas que sustentaram essa prática.

Entende-se que as estratégias de intervenção na saúde individual e coletiva, como aquelas implementadas pela educação sanitária no período estudado, não foram uma prerrogativa dos tempos modernos do século XX. Desde meados do século XVIII, se deu «o início das preocupações e intervenções do Estado com relação à saúde pública» ${ }^{1}$ quando o conhecimento sobre o governo dos homens, passou a envolver, para além da noção de polícia, saberes relacionados a melhorar, prolongar e tornar mais produtiva a vida dos súditos.

Desse modo, o movimento higienista, levado a cabo nas primeiras décadas do século XX em grande parte do mundo, foi um dos mais ambiciosos projetos de intervenção social que a modernidade ocidental

\footnotetext{
1 Rafael Mantovani e Maria Cristina da Costa Marques, «Higiene como prática individual e como instrumento de Estado», História, Ciências, Saúde - Manguinhos 27 (2), (2020): 345. https://doi. org/10.1590/s0104-59702020000200002.
} 
experimentou, ${ }^{2}$ projeto esse sustentado por ações de educação sanitária, com forte influência dos Estado Unidos da América.

O referido projeto em 1919 já difundia preceitos da educação em saúde, termo análogo à educação sanitária, que, entre outras características, ${ }^{3}$ adotava princípios científicos pautados nos avanços da microbiologia e imunologia, associados a métodos pedagógicos com vistas a promover modelos de comportamento individuais e coletivos. ${ }^{4}$

No Brasil, a institucionalização das estratégias de educação sanitária, se oficializou a partir do ano de 1923 com a criação e estruturação do Serviço de Propaganda e Educação Sanitária (SPES), vinculado ao Departamento Nacional de Saúde Pública (DNSP), órgão máximo regulador de ações de saúde, criado na então Capital da República à época, Rio de Janeiro, sendo substituído em1941 pelo Serviço Nacional de Educação Sanitária (SNES), reestruturado em 1962.55

\section{A REGULAMENTAÇÃO DA EDUCAÇÃO SANITÁRIA EM SÃO PAULO, BRASIL}

Apesar das estratégias do SPES e SNES, estarem centralizadas à federação, buscando coordenar e propagar, ainda que de modo incipiente, aos estados que compunham a nação brasileira ideais atinentes à construção de uma "consciência sanitária» nacional, foi em um dos seus estados, especificamente no estado de São Paulo, que a educação sanitária se firmou como um dos projetos mais abrangentes e estruturantes da Saúde Pública. O órgão estadual, denominado de Serviço de Propaganda e Educação Sanitária do Departamento de Saúde do Estado de São Paulo (SPES-DSESP), desde a década de 1920 já atuava na publicação

\footnotetext{
${ }^{2}$ Márcia Guedes Soares, «A Política de Educação do Serviço Sanitário de São Paulo entre a República Velha e o Estado Novo», Tesis de maestría, Faculdade de Educação da Universidade Estadual de Campinas, 2017.

3 Vanderlei Sebastião de Souza, «Arthur Neiva e a questão nacional nos anos 1910 e 1920», História, Ciências, Saúde-Manguinhos 16(1)(2009):249-264.https://doi.org/10.1590/S0104-59702009000500012.

${ }_{4}^{4}$ Rogério Dias Renovato e Maria Helena Salgado Bagnato, «Práticas educativas em saúde e a constituição de sujeitos ativos», Texto \& Contexto - Enfermagem 19 (3) (2009): 554-562. https://doi. org/10.1590/S0104-07072010000300018.

5 Érica Mello de Souza, «Educação sanitária: orientações e práticas federais desde o Serviço de Propaganda e Educação Sanitária ao Serviço Nacional de Educação Sanitária (1920-1940)». Tesis de maestría, Casa de Oswaldo Cruz, 2012.
} 
de cartazes, folhetos e boletins, como estratégia de divulgação de hábitos de vida saudável e ações de combate a endemias. ${ }^{6}$

Nessa perspectiva, cabe destacar as ações de personalidades como Arthur Neiva (1917) e Geraldo de Paula Souza (1925). Arthur Neiva, ao assumir a direção geral do principal órgão estadual de saúde - Serviço Sanitário de São Paulo, por meio da Lei no 1.596 , de 29 de dezembro de 1917, propôs a reorganização daquele serviço, criando 11 Delegacias de Saúde, cinco delas na capital do estado e demais nas maiores cidades do interior. ${ }^{77}$

Um ano mais tarde, em 1918, foi criado o Código Sanitário do Estado de São Paulo, composto de 800 artigos, que propôs medidas de controle e regulação das pessoas nas cidades e na zona rural, ${ }^{8}$ ainda sob à égide de uma lógica de vigilância policialesca, composto por inúmeras regras prescritivas direcionadas à normatização da vida individual e coletiva. ${ }^{9}$

Embora as poucas estratégias que articulavam educação e regulação de hábitos sanitários individuais e coletivos estivessem presentes e alinhadas a uma lógica mais coercitiva, interventiva e policialesca, em 1925, presenciou-se uma ruptura no entendimento dessas práticas sanitárias no Estado de São Paulo, quando Geraldo Horácio de Paula Souza, em consonância à influência da Fundação Rockfeller, propôs a reestruturação global do Serviço Geral de Saúde Pública do estado, por meio do Decreto n. 3.876, que determinou à Inspetoria de Educação Sanitária «promover a formação da consciência sanitária da população em geral». ${ }^{10}$

\footnotetext{
6 Maria Cristina da Costa Marques, Danilo Fernandes Brasileiro e Suzana César Gouveia Fernandes, «Informação e disciplina: a Coletânea de Educação Sanitária do estado de São Paulo, Brasil (1939-1952)», Interface 21 (61), (2017): 397-410. https://doi.org/10.1590/1807-57622016.0100.
}

\footnotetext{
7 Rodolfo Santos Mascarenhas, «Contribuição para o estudo da administração estadual em São Paulo». Tesis de docencia libre, Faculdade de Higiene e Saúde Pública, Universidade de São Paulo, 1949.

8 Ivomar Gomes Duarte, «O código sanitário estadual de 1918 e a epidemia de gripe espanhola», Cadernos de História da Ciência 5 (1), (2009): 55-73. http://periodicos.ses.sp.bvs.br/scielo.php?script=sci_arttext\&pid=S1809 763420090 00100004\&lng=pt\&nrm=is o (consultado el 23-09-2021).

9 Emerson Elias Merhy, A saúde pública como política (São Paulo: Hucitec, 2006).

10 Nelly Martins Ferreira Candeias, «Evolução histórica da educação em saúde como disciplina de ensino na Faculdade de Saúde Pública da Universidade de São Paulo - 1925 a 1967», Revista de Saúde Pública 22 (4), (1988): 350. https://doi.org/doi: 10.1590/S0034-89101988000400013.
} 
Cabia a este serviço atuar junto ao indivíduo e coletividade, por meio de promoções de atividades nas unidades, de Centros de Saúde, em visitas domiciliares, em estabelecimentos escolares, hospitalares e fabris. A educação sanitária era a partir daquele momento o elemento chave utilizado pelo estado para normatizar hábitos de vida e consequentemente obter impactos nas condições sanitárias da população, ${ }^{11}$ e a reforma proposta por Paula Souza, foi reforçada através do Decreto n. 18.165 de 22 de junho de 1948, com ampliação da rede distrital dos Centros de Saúde, fortalecendo o modelo de promoção saúde defendido pelo sanitarista. ${ }^{12}$

Apesar da solidificação das ações propostas pela Reforma Paula Souza notava-se em meados da década de 1950, que a complexidade do cenário sanitário do estado de São Paulo havia se modificado, dado crescente industrialização e adensamento populacional, ${ }^{13}$ dilemas esses refletidos na administração sanitária paulista, que notadamente sofria sérios problemas de planejamento e excessiva desordem. ${ }^{14}$

Desse modo, por meio do Decreto $\mathrm{n}^{\circ}$ 48.162, de 3 de julho de 1967, Walter Sidney Leser, secretário de saúde do Estado de São Paulo, apontava para uma situação de deterioração da máquina pública e suas repercussões na vida dos cidadãos paulistas, propondo assim uma ampla reforma de saúde, através da descentralização executiva das ações de saúde pública, com criações de Distritos Sanitários, variando em termos gerais de 40.000 a 150.000 habitantes, que seria chefiado por médico-sanitarista de carreira, em regime de dedicação exclusiva, além da criação de Centros de Saúde Distritais. ${ }^{15}$

\footnotetext{
11 Mantovani y Marques, «Higiene como prática individual».

12 Fábio de Oliveira Almeida, «Reforma Sanitária e política paulista: as relações entre os processos de profissionalizações dos médicos de São Paulo e políticas de saúde do governo estadual Adhemar de Barros». Tesis de maestría, Universidade Federal de São Carlos, 2010.

13 Guilherme Arantes Mello, Nelson Ibanez e Ana Luiza d’Ávila Viana, «Um olhar histórico sobre a questão regional e os serviços básicos de saúde no Estado de São Paulo», Saúde e Sociedade 20 (4), (2011): 853-866. https:// doi.org/10.1590/S0104-12902011000400004.

14 André Mota, Lilia Blima Schraiber e José Ricardo de Carvalho Mesquita Ayres, «A Reforma Leser: a arquitetura de um projeto de saúde pública paulista, 1967-1979»», Saúde e Sociedade 28 (4), (2019): 267-283. https://doi. org/10.1590/s0104-12902019190043.

15 Mota, Schraiber y Ayres, «A Reforma Leser».
} 
Portanto, a premissa argumentativa que justifica essa investigação é de que, o período entre 1917 e 1967, permeado por inúmeras reformas e transformações, foi de substancial importância à regulamentação da saúde pública no estado de São Paulo. Não obstante, foi nesse período que se testemunhou a gênese, implementação e aperfeiçoamento das ações de educação sanitária em todo estado de São Paulo, de modo que não por acaso, tornou-se ferramenta primordial, viabilizadora da intervenção e modulação de comportamentos individuais e coletivos legitimados e pretendidos pelo estado, em consonância à consolidação de um ambicioso projeto desenvolvimentista social e econômico.

\section{PERCURSO METODOLÓGICO}

Trata-se de uma revisão integrativa da literatura, cuja utilização metodológica possibilita elencar os conhecimentos sobre temática específica, uma vez que é conduzida com intuito de identificar, analisar e sintetizar resultados de estudos independentes sobre o mesmo tema. ${ }^{16}$

Com base na pergunta norteadora - Quais foram as concepções de educação sanitária e as influências ideológicas, políticas e científicas que sustentaram essa prática entre os anos de 1917 a 1967 no estado de São Paulo, Brasil? -, construíram-se os descritores - educação sanitária, história, educação em saúde e São Paulo -, e se procedeu à busca no acervo digital da Biblioteca Virtual de Saúde (BVS), plataforma de fontes de informação de bases de dados bibliográficas produzidas em rede e em cooperação com bases referenciadas e indexadas da área. Foram encontrados 214 artigos, dos quais, após categorização, selecionaram-se 41 que discutiam a educação sanitária em perspectiva histórica.

Na classificação de quatro categorias temáticas, foram selecionados 32 artigos, uma vez que investigavam a história da educação sanitária paulista e, posteriormente, recortado o corpus documental da presente revisão integrativa, com o total de 14 artigos, com conteúdo acerca de concepções da educação sanitária paulista ao longo da história e o recorte histórico estudado (1917-1967), disponíveis nas base de dados

\footnotetext{
16 Marcela Tavares de Souza, Michelly Dias da Silva e Rachel de Carvalho, «Revisão integrativa: o que é e como fazer», Einstein 8 (1), (2010): 102-106. https://doi.org/doi: 10.1590/s1679-45082010rw1134.
} 
indexadas na BVS: LILACS, MEDLINE e Repositório da Secretaria de Estado de Saúde de São Paulo.

A análise foi seguida pela identificação e extração de excertos que apontassem elegíveis concepções de educação sanitária paulista. Ao fim dessa fase de identificação e extração de alegações teóricas dos respectivos artigos, tais excertos foram submetidos a criterioso julgamento e classificados por similaridade e pertinência teórica, permitindo assim a construção de categorias, descritas e interpretadas criticamente.

\section{Resultados e discussão}

A análise do corpus documental (Quadro 1) selecionado possibilitou definir duas categorias para sintetizar as concepções percebidas de educação sanitária difundidas no estado de São Paulo entre os anos de 1917 e 1967, a saber: 1 - Educação Sanitária como Expressão da Eugenia e2 - Educação Sanitária como Expressão da Biopolítica.

\section{A EDUCAÇÃO SANITÁRIA COMO EXPRESSÃO DA EUGENIA}

As referências encontradas nos artigos alusivas à eugenia foram diversas, com referência a concepção de Francis Galton como a ciência da hereditariedade que tem seu conceito balizado no aprimoramento e perpetuação de um modelo superior de raça, conforme atributos específicos de um conjunto populacional. ${ }^{17}$ As características biológicas, comportamentais, intelectuais ou artísticas, por exemplo, segundo a concepção eugênica supracitadas são julgadas favoráveis ou desfavoráveis para a reprodutibilidade da raça. Nesse sentido, constrói-se a marginalização científica e social de alguns traços populacionais, como o alcoolismo, prostituição e demência; atribuindo na herança o único pressuposto que distinguiria os descendentes aptos e não aptos para formatar um ideal de povo potente e capaz resistir as adversidades do ambiente. ${ }^{18}$

\footnotetext{
17 Valdeir Del Cont, «Francis Galton: eugenia e hereditariedade», Scientiae Studia 6 (2), (2008): 201-218. https:// doi.org/ 10.1590/S1678-31662008000200004.

18 Cont, «Francis Galton».
} 
Quadro 1. Lista dos 14 artigos incluídos na revisão, segundo título, periódico, local, ano e objetivos

\begin{tabular}{|c|c|c|c|}
\hline Título & Periódico & $\begin{array}{c}\text { Cidade } \\
\text { Ano }\end{array}$ & Objetivos \\
\hline $\begin{array}{l}\text { Eschema da } \\
\text { organizaçao } \\
\text { sanitaria do } \\
\text { Estado de Sao } \\
\text { Paulo }\end{array}$ & $\begin{array}{l}\text { Boletín de la } \\
\text { Oficina } \\
\text { Sanitaria } \\
\text { Panamericana } \\
\text { (OSP) } 15 \text { (1) }\end{array}$ & $\begin{array}{l}\text { São Paulo } \\
1936\end{array}$ & $\begin{array}{l}\text { Traçar o panorama da } \\
\text { organização sanitária no Estado } \\
\text { de São Paulo esclarecendo os } \\
\text { problemas técnicos- } \\
\text { administrativos e os } \\
\text { encaminhamentos para as } \\
\text { necessidades de vida e saúde }\end{array}$ \\
\hline $\begin{array}{l}\text { Evolução histórica } \\
\text { da educação em } \\
\text { saúde como } \\
\text { disciplina de } \\
\text { ensino na } \\
\text { Faculdade de } \\
\text { Saúde Pública da } \\
\text { Universidade de } \\
\text { São Paulo - } 1925 \\
\text { a } 1967\end{array}$ & $\begin{array}{l}\text { Revista Saúde } \\
\text { Pública } 22(4)\end{array}$ & $\begin{array}{l}\text { São Paulo } \\
1988\end{array}$ & $\begin{array}{l}\text { Analisar cartas, recortes de } \\
\text { jornais, atas, fotografias, } \\
\text { relatórios, projetos de lei e } \\
\text { outros documentos de } \\
\text { significativo valor para a história } \\
\text { desta Instituição, no período de } \\
1918 \text { a } 1945\end{array}$ \\
\hline $\begin{array}{l}\text { "De pequenino é } \\
\text { que se torce o } \\
\text { pepino»: a infância } \\
\text { nos programas } \\
\text { eugênicos da Liga } \\
\text { Brasileira de } \\
\text { Higiene Mental }\end{array}$ & $\begin{array}{l}\text { História } \\
\text { ciências } \\
\text { saúde- } \\
\text { Manguinhos } \\
7 \text { (1) }\end{array}$ & $\begin{array}{l}\text { Rio de } \\
\text { Janeiro } \\
2000\end{array}$ & $\begin{array}{l}\text { Discutir as propostas de } \\
\text { intervenção na problemática } \\
\text { infantil apresentadas pela Liga } \\
\text { Brasileira de Higiene Mental } \\
\text { (LBHM), instituição criada no } \\
\text { começo da década de } 1920 \text { que } \\
\text { reunia a elite da psiquiatria } \\
\text { brasileira, mas também alguns } \\
\text { médicos e intelectuais em geral }\end{array}$ \\
\hline $\begin{array}{l}\text { A Fundaçäo } \\
\text { Rockefeller e os } \\
\text { serviços de saúde } \\
\text { em Säo Paulo } \\
\text { (1920-30): } \\
\text { perspectivas } \\
\text { históricas }\end{array}$ & $\begin{array}{l}\text { História } \\
\text { ciências } \\
\text { saúde- } \\
\text { Manguinhos } \\
9(3)\end{array}$ & $\begin{array}{l}\text { Rio de } \\
\text { Janeiro } \\
2002\end{array}$ & $\begin{array}{l}\text { Fazer uma apresentação } \\
\text { histórica das políticas de saúde } \\
\text { implementadas em São Paulo } \\
\text { nas décadas de } 1920 \text { e } 1930, \\
\text { procurando uma compreensão } \\
\text { mais apurada dos processos de } \\
\text { formulação das políticas } \\
\text { governamentais concernentes às } \\
\text { ações de saúde }\end{array}$ \\
\hline
\end{tabular}




\begin{tabular}{|c|c|c|c|}
\hline Título & Periódico & $\begin{array}{c}\text { Cidade } \\
\text { Ano }\end{array}$ & Objetivos \\
\hline $\begin{array}{l}\text { A educação } \\
\text { sanitária como } \\
\text { profissão feminina }\end{array}$ & $\begin{array}{l}\text { Cadernos } \\
\text { Pagu } 24\end{array}$ & $\begin{array}{l}\text { Campinas } \\
2005\end{array}$ & $\begin{array}{l}\text { Retraçar a trajetória de Maria } \\
\text { Antonieta de Castro, profissional } \\
\text { cuja atuação se confunde com a } \\
\text { implementação de um novo } \\
\text { modelo de intervenção em saúde } \\
\text { pública, instituído pela Reforma } \\
\text { Paula Souza em } 1925\end{array}$ \\
\hline $\begin{array}{l}\text { A fotografia como } \\
\text { instrumento do } \\
\text { trabalho do } \\
\text { higienista (Säo } \\
\text { Paulo, primeira } \\
\text { metade do século } \\
X X \text { ) }\end{array}$ & $\begin{array}{l}\text { História } \\
\text { ciência } \\
\text { saúde- } \\
\text { Manguinhos } \\
13(2)\end{array}$ & $\begin{array}{l}\text { Rio de } \\
\text { Janeiro } \\
2006\end{array}$ & $\begin{array}{l}\text { Discutir e analisar o uso da } \\
\text { fotografia em seus múltiplos } \\
\text { aspectos e possibilidades na } \\
\text { prática do higienista/sanitarista, } \\
\text { ao passo que alerta para } \\
\text { necessidade de preservação, } \\
\text { organização e disponibilização } \\
\text { dos acervos históricos da saúde } \\
\text { pública no Brasil }\end{array}$ \\
\hline $\begin{array}{l}\text { A guerra e as } \\
\text { laranjas: uma } \\
\text { palestra } \\
\text { radiofônica sobre o } \\
\text { valor alimentício } \\
\text { das frutas } \\
\text { nacionais (1940) }\end{array}$ & $\begin{array}{l}\text { História } \\
\text { ciência } \\
\text { saúde- } \\
\text { Manguinhos } \\
14(4)\end{array}$ & $\begin{array}{l}\text { Rio de } \\
\text { Janeiro } \\
2007\end{array}$ & $\begin{array}{l}\text { Apresentar e discutir a } \\
\text { experiência do uso do rádio pelos } \\
\text { sanitaristas, em especial, Geraldo } \\
\text { Horácio de Paula Souza, em } 16 \\
\text { de abril de 1940, que foi aos } \\
\text { microfones da Rádio Educadora } \\
\text { Paulista e, por meio de palestra, } \\
\text { defendeu o valor nutritivo e a } \\
\text { necessidade de consumo da } \\
\text { laranja como ato patriótico }\end{array}$ \\
\hline $\begin{array}{l}\text { Higienizando a } \\
\text { raça pelas mãos da } \\
\text { educação ruralista: } \\
\text { o caso do Grupo } \\
\text { Escolar Rural do } \\
\text { Butantan em } 1930\end{array}$ & $\begin{array}{l}\text { Interface } \\
\text { (Botucatu) } \\
14(32)\end{array}$ & $\begin{array}{l}\text { Botucatu } \\
2007\end{array}$ & $\begin{array}{l}\text { Apresentar a experiência do } \\
\text { Grupo Escolar Rural do } \\
\text { Butantan, na cidade de São } \\
\text { Paulo, nos anos 1930, que tinha } \\
\text { um plano educacional de base } \\
\text { higienista, que atrelou assuntos } \\
\text { do campo à educação sanitária, } \\
\text { com vistas na produção de } \\
\text { cidadãos brasileiros } \\
\text { «eugenicamente bem } \\
\text { formatados» }\end{array}$ \\
\hline
\end{tabular}




\begin{tabular}{|c|c|c|c|}
\hline Título & Periódico & $\begin{array}{c}\text { Cidade } \\
\text { Ano }\end{array}$ & Objetivos \\
\hline $\begin{array}{l}\text { Educação em } \\
\text { saúde: uma } \\
\text { reflexão histórica } \\
\text { de suas práticas }\end{array}$ & $\begin{array}{l}\text { Ciência \& } \\
\text { Saúde } \\
\text { Coletiva } 15(5)\end{array}$ & $\begin{array}{l}\text { Rio de } \\
\text { Janeiro } \\
2010\end{array}$ & $\begin{array}{l}\text { Contextualizar as transformações } \\
\text { ocorridas nas práticas de } \\
\text { educação em saúde desde o } \\
\text { cenário político no final do } \\
\text { século XIX, quando se } \\
\text { organizaram as primeiras } \\
\text { iniciativas ampliadas do Estado } \\
\text { brasileiro no campo da saúde, } \\
\text { até a criação do Sistema Único } \\
\text { de Saúde }\end{array}$ \\
\hline $\begin{array}{l}\text { A educação } \\
\text { sanitária nos } \\
\text { Centros De Saúde } \\
\text { De São Paulo } \\
\text { (1925-1930): } \\
\text { práticas e sujeitos }\end{array}$ & $\begin{array}{l}\text { História da } \\
\text { Enfermagem: } \\
\text { Revista } \\
\text { Eletrônica } \\
2(2)\end{array}$ & $\begin{array}{l}\text { São Paulo } \\
2011\end{array}$ & $\begin{array}{l}\text { Compreender e analisar a prática } \\
\text { de educação sanitária e suas } \\
\text { implicações nos centros de saúde } \\
\text { de São Paulo no período de } 1925 \\
\text { a } 1930\end{array}$ \\
\hline $\begin{array}{l}\text { O Plano de } \\
\text { Educação } \\
\text { Higiênica de } \\
\text { Belisário Penna. } \\
\text { 1900-1930 }\end{array}$ & $\begin{array}{l}\text { Dynamis } \\
32(1)\end{array}$ & $\begin{array}{l}\text { Granada } \\
2012\end{array}$ & $\begin{array}{l}\text { Descrever e analisar as principais } \\
\text { idéias formuladas por Penna no } \\
\text { período entre } 1900 \text { e } 1930\end{array}$ \\
\hline $\begin{array}{l}\text { Pensamento } \\
\text { clássico da saúde } \\
\text { pública paulista } \\
\text { na era dos centros } \\
\text { de saúde e } \\
\text { educação sanitária }\end{array}$ & $\begin{array}{l}\text { Revista Saúde } \\
\text { Pública } 46(4)\end{array}$ & $\begin{array}{l}\text { São Paulo } \\
2012\end{array}$ & $\begin{array}{l}\text { Discutir o pensamento dos } \\
\text { sanitaristas Geraldo de Paula } \\
\text { Souza, Rodolfo Mascarenhas e } \\
\text { Reinaldo Ramos, representantes } \\
\text { ilustres do «pensamento } \\
\text { clássico» da saúde pública de } \\
\text { São Paulo, em meio à introdução } \\
\text { do modelo do Centro de Saúde } \\
\text { distrital pela reforma do Serviço } \\
\text { Sanitário em } 1925\end{array}$ \\
\hline $\begin{array}{l}\text { Informação e } \\
\text { disciplina: a } \\
\text { Coletânea de } \\
\text { Educação } \\
\text { Sanitária do } \\
\text { estado de São } \\
\text { Paulo, Brasil } \\
\text { (1939-1952) }\end{array}$ & $\begin{array}{l}\text { Interface } \\
\text { (Botucatu) } \\
21(61)\end{array}$ & $\begin{array}{l}\text { Botucatu } \\
2017\end{array}$ & $\begin{array}{l}\text { Caracterizar e identificar } \\
\text { indícios do discurso } \\
\text { disciplinador na coletânea de } \\
\text { educação sanitária, distribuída } \\
\text { em todo o Estado de São Paulo } \\
\text { entre os anos de } 1939 \text { e } 1952\end{array}$ \\
\hline
\end{tabular}




\begin{tabular}{|c|c|c|c|}
\hline Título & Periódico & $\begin{array}{c}\text { Cidade } \\
\text { Ano }\end{array}$ & Objetivos \\
\hline $\begin{array}{l}\text { O governo do } \\
\text { Estado de São } \\
\text { Paulo se interessa } \\
\text { pelo teu filho: o } \\
\text { ideal de mãe } \\
\text { paulista entre } 1937 \\
\text { e } 1964\end{array}$ & $\begin{array}{l}\text { História da } \\
\text { enfermagem: } \\
\text { Revista } \\
\text { eletrônica } \\
9 \text { (1) }\end{array}$ & $\begin{array}{l}\text { São Paulo } \\
2018\end{array}$ & $\begin{array}{l}\text { Analisar e descrever conceitos e } \\
\text { padrões de comportamentos, } \\
\text { construídos e disseminados pelo } \\
\text { Livro das Mãezinhas }\end{array}$ \\
\hline
\end{tabular}

Mota aponta que «a eugenia foi recebida e acolhida no Brasil, especialmente no Estado de São Paulo, nas diversas especialidades médicas e entendida como uma tecnologia científica que precisava ser implementada, desde estudos obstétricos às ações dos cirurgiões, nas ações e intervenções sanitárias e, também, nas experiências psiquiátricas». ${ }^{19}$

A Sociedade Eugênica de São Paulo foi criada em 1918, representando o marco na institucionalização da eugenia no Brasil, o que permitiu a sistematização de trabalhos ligados ao tema. Kobayashi e colaboradores apontam que "falar sobre eugenia conferia modernidade ao meio científico e intelectual das primeiras décadas do século XX». ${ }^{20}$ Médicos, juristas e educadores se constituíam como os principais interessados e defensores da ideia do movimento de melhoria racial, e, também, evolução, progresso e civilização. ${ }^{21}$

A influência desse modelo ideológico sobre a educação sanitária em São Paulo, viabilizou a idealização de um tipo de povo que construiria o estado, trazendo o progresso, com melhoramento de raça. ${ }^{22}$ Assim a educação sanitária auxiliou na disseminação do civismo e da higiene, em um estado que deveria ser habitado «por homens e mulheres cultos,

\footnotetext{
19 André Mota, «Quem tem medo da eugenia? Permanências discursivas de uma prática inacabada», en As doenças e os medos sociais, org. Yara Nogueira Monteiro e Maria Luiza Tucci Carneiro (São Paulo: Fap-Unifesp, 2012 ), 230.

20 Elisabete Kobayashi, Lina Rodrigues de Faria e Maria Conceição Costa, «Eugenia e Fundação Rockefeller no Brasil: a saúde como proposta de regeneração nacional», Sociologias 11 (22), (2009): 319. https://doi.org/ 10.1590/ S1517-45222009000200012.

${ }^{21}$ Kobayashi, Faria e Costa «Eugenia e Fundação Rockefeller no Brasil».

22 Rogério Renovato e Maria Bagnato, «A educação sanitária nos Centros de Saúde de São Paulo (1925-1930): práticas e sujeitos», História da Enfermagem 2 (2), (2011): 61-71. https://pesquisa.bvsalud.org/portal/resource/pt/ biblio-1028940 (consultado el 23-09-2021).
} 
livres de epidemias e endemias, aptos ao trabalho, ou seja, uma raça elevada e comparável às nações industrializadas do hemisfério norte».23

Reis, ${ }^{24}$ por sua vez, apontou que desde o início do século XX se consolidavam paulatinamente vertentes teóricas e iniciativas direcionadas a medidas que contemplassem o branqueamento da população, com vistas à produção de um padrão nacional e também paulista forjado em atributos eugênicos, e que seriam responsáveis para sanear não apenas o meio urbano, mas também o rural, subordinadas aos anseios de modernização da estrutura econômico-social paulista. ${ }^{25}$

Já Marques et al. afirmaram que a preocupação em lidar com a higiene rural em São Paulo, não por acaso, revelou na primeira metade do século XX intencionalidades em higienizar e sanear o referido espaço por meio da difusão de preceitos eugênicos e higiênicos, de modo a contribuir com a permanência do homem no ambiente rural, atenuando o êxodo rural e mais ainda, capacitando e disciplinando aqueles cidadãos, com vistas no alcance da modernização que estava por vir. ${ }^{26}$

Essa preocupação em educar higienicamente os habitantes do espaço rural do Estado de São Paulo, foi objeto de outra profunda análise realizado por Mota, ${ }^{27}$ sobretudo quando trouxe a experiência de um grupo escolar rural na década de 1930, que dentre inúmeras peculiaridades, identificou os preceitos eugênicos e higiênicos nos livros e documentos utilizados pelos educadores rurais, cuja estratégica didáticas contemplavam à produção de cidadãos paulistas eugenicamente bem formatados, cujo ensinamentos eram marcados «por tecnologias urbanas e modernizantes, atreladas a uma ideologia nacionalista, com técnicas de melhoramento racial de aves e plantas mescladas às medidas higiênicas em que deveriam estar submetidos seus alunos». ${ }^{28}$

\footnotetext{
${ }^{23}$ Renovato e Bagnato, «A educação sanitária», 70.

24 José Roberto Franco Reis, «"De pequenino é que se torce o pepino”: a infância nos programas eugênicos da Liga Brasileira de Higiene Mental», História, Ciências, Saúde - Manguinhos 7 (1), (2000): 135-157. https://doi.org/ 10.1590/S0104-59702000000200007.

25 Renovato e Bagnato, «Práticas educativas em saúde».

26 Marques, Brasileiro e Fernandes, «Informação e disciplina».

27 André Mota, «Higienizando a raça pelas mãos da educação ruralista: o caso do Grupo Escolar Rural do Butantan em 1930», Interface 14 (32), (2010): 9-22. https://doi.org/10.1590/S1414-32832010000100002.

28 Mota, «Higienizando a raça», 19.
} 
No intuito de atingir o modelo pretendido de «povo forte e de raça superior», o projeto de eugenia por meio da educação sanitária apontava a necessidade de superar algumas mazelas impregnadas no corpo coletivo social.

Nesse sentido Santos, ${ }^{29}$ afirmou que na primeira metade do século $\mathrm{XX}$, difundiam-se teorias de seleção racial, objetivando o embranquecimento populacional por meio de princípios eugênicos, em articulação com a educação sanitária, que por sua vez, propiciaram a manutenção de uma nova ordem, já que a ausência de educação era atribuída como uma das principais causas de pobreza e responsável pela propagação de inúmeras doenças, sendo, portanto, necessário a difusão da educação sanitária. ${ }^{30}$

Seguindo essa perspectiva apregoada na época, que deu suporte epistemológico para institucionalização da educação sanitária alinhada à preceitos eugênicos, como o de regeneração da raça, as ações promovidas entre centros de saúde e escolas primárias na primeira metade do século XX, fundamentava-se sobretudo em um modelo de eugenia preventiva, uma vez que se acreditava que «a educação sanitária semeia, a raça colherá o futuro». ${ }^{31}$

Outro aspecto tensionado pela educação sanitária eugênica foi o apoio à formação de educadoras sanitárias, cujo papel foi instrumentalizar e tornar higiênica a cultura brasileira, atribuindo certos valores, morais e hábitos como justificativa para um melhor padrão e qualidade de vida e saúde, uma vez que, ao analisar criticamente a relação da formação do profissional de educação sanitária com o gênero feminino, Rocha ${ }^{32}$ destacou que eram reconhecidas naquela época como «mensageiras da saúde, incumbidas do sublime apostolado de levar a todos os cantos a boa nova da regeneração da raça».33

\footnotetext{
${ }^{29}$ Ricardo Augusto dos Santos «O Plano de Educação Higiênica de Belisário Penna. 1900-1930», Dynamis 32 (1), (2012): 45-68. https://doi.org 10.4321/S0211-95362012000100003.

30 Santos, «O Plano de Educação Higiênica».

31 Heloísa Helena Pimenta Rocha, «A educação sanitária como profissão feminina», Cadernos Pagu 24 (2005): 79. https://doi.org 10.1590/S0104-83332005000100005.

32 Rocha, "A educação sanitária».

33 Rocha, "A educação sanitária», 78.
} 
As profissionais recrutadas, tratadas como «mensageiras da saúde» ${ }^{34}$ eram formadas com o objetivo de disseminar e inculcar hábitos higiênicos na população paulista, fosse em fábricas, recém-criados centros de saúde, escolas e até as residências, no intuito de atingir o ideal de raça saneada, civilizada e por assim dizer normatizada. ${ }^{35}$

Além do papel dessas educadoras sanitárias, conceitos eugênicos e científicos de saúde geralmente eram divulgados por rádio, ${ }^{36}$ manuais, livros e/ou cartilhas, pois permeavam a reprodução, planejamento e cuidado com as crianças do país; vislumbrando-se como uma estratégia forte de saúde pública, em que se apresentava o perfil de criança e infância a ser produzido e alcançado pela classe média trabalhadora de São Paulo, iconograficamente representado por modelos de crianças de cor branca, cabelos claros, lisos ou cacheados e bem nutrida, ou seja uma criança bem cuidada em um contexto familiar bem estruturado. ${ }^{37}$

Outro contexto em que se fizeram presentes as estratégias de educação sanitária, alinhadas à lógica eugênica, foi referente à chamada «higiene mental», em que, analisando ações da Liga Brasileira de Higyene Mental, composta pela elite da psiquiatria brasileira no início da década de 1920, Reis ${ }^{38}$ constatou uma concepção de educação sanitária que rotulava caracteres de comportamentos positivos e negativos a ser adotados pela sociedade, destinadas sobretudo ao público infantil, que tanto buscavam orientar e instruir tecnicamente professoras primárias com noções de psicologia, acreditando que assim se multiplicariam «as fontes de propaganda dos grandes princípios que põem na educação os fundamentos da higiene mental». ${ }^{39}$

\footnotetext{
34 Rocha, «A educação sanitária», 78.

35 Danilo Fernandes Brasileiro, Rodrigo Contrera Ramos, Bianca Oliveira Ferro e Maria Cristina da Costa Marques, «O governo do estado de São Paulo se interessa pelo teu filho: o ideal de mãe em São Paulo de 1937 a 1964», História da Enfermagem 9 (1), (2018): 20-34. https://pesquisa.bvsalud.org/portal/resource/pt/biblio-948334.

36 Jaime Rodrigues e Maria da Penha Costa Vasconcellos, «A guerra e as laranjas: uma palestra radiofônica sobre o valor alimentício das frutas nacionais (1940)», História, Ciência, Saúde-Manguinhos 14 (4), (2007): 1413. https:// doi.org/10.1590/S0104-59702007000400016.

37 Brasileiro et al., «O governo do estado de São Paulo».

38 Reis, «"De pequenino é que se torce o pepino"».

39 Reis, «"De pequenino é que se torce o pepino”», 140.
} 
Fato é que, os pretextos eugênicos associados à educação sanitária foram ferramentas que subsidiaram à viabilização, legitimidade e infiltração da chamada moderna ciência da higiene no senso comum e no comportamento dos brasileiros do estado de São Paulo, disseminando conceitos e padrões no coletivo social, considerando-os como supremos ideais da civilização e do progresso. ${ }^{40}$

\section{A EDUCAÇÃO SANITÁRIA COMO EXPRESSÃO DA BIOPOLÍTICA}

Michel Foucault consolidou o conceito de Biopoder como «o conjunto dos mecanismos pelos quais aquilo que, na espécie humana, constitui suas características biológicas fundamentais, vai poder entrar numa política, numa estratégia política, numa estratégia geral do poder».41

Dessa maneira, a promoção de um conceito de sociedade, padrões de comportamentos, assim como a adequação dos fenômenos biológicos da população como sexualidade, nascimento, longevidade ou condição saúde-doença; hierarquiza e partilha a vida em domínios de poder e jurisdição. Tudo isso, garante, em última instância, a tessitura de uma força produtiva e, assim, econômica de um Estado moderno. ${ }^{42}$

A presença das doenças no corpo e no imaginário social era derivada, segundo a concepção acima, de uma certa cultura popular que trazia o subdesenvolvimento do povo e sua morte.

Desse modo, para governabilizar as enfermidades, era preciso docilizar os corpos associando educação, saúde e doença, pois, como afirmaram Silva et al.,43 a população era vista como a principal causadora de doenças nas grandes cidades e, portanto, dever-se-ia romper com a ignorância e a falta de informação dos cidadãos, desafio que cabia à educação sanitária e a seu aparato tecnológico normativo.

\footnotetext{
40 Rocha, «A educação sanitária».

${ }^{41}$ Michel Foucault, Segurança, território, população: curso dado no Collège de France (1977-1978) (São Paulo: Martins Fontes, 2008), 3.

42 Rafael Nogueira Furtado y Juliana Camilo Aparecida de Oliveira, «O conceito de biopoder no pensamento de Michel Foucault», Subjetividades 16 (3), (2016): 34-44. https://doi.org/10.5020/23590777.16.3.34-44.

43 Cristiane Maria da Costa Silva, Marcelo de Castro Meneghim, Antonio Carlos Pereira e Fábio Luiz Mialhe, «Educação em saúde: uma reflexão histórica de suas práticas», Ciência \& Saúde Coletiva 15 (5), (2010): 2539-2550. https://doi.org/10.1590/S1413-81232010000500028.
} 
Marques, Brasileiro e Fernandes ${ }^{44}$ concluíram que, na primeira metade do século XX, a educação sanitária, se valeu de inúmeras estratégias, permeadas de conceitos prescritivos e disciplinares, modelando comportamentos e padronizando as práticas de saúde da população.

Nessa mesma perspectiva analítica, Renovato e Bagnato ${ }^{45}$ entenderam que as ações de educação sanitária comumente difundidas atuaram como um dispositivo governamental de poder sobre o corpo e sobre a vida, sendo justificada esse aparato intervencionista da educação sanitária, pelo fato de que a ausência de educação formal, eram barreiras substanciais que dificultavam a adoção de hábitos considerados saudáveis e consequentemente aquisição da consciência sanitária.

Desse modo, sob a justificativa de conter doenças e epidemias, urgia ao Estado fazer-se presente no cotidiano do povo. Nessa perspectiva, formaram-se recursos humanos e se disseminaram burocracias sanitárias como mecanismo de institucionalização de serviços de saúde pública, sobretudo entre as décadas de 1920 e 1930, quando, por meio da criação das Inspetorias Sanitárias, almejava-se a propagação e a aquisição de uma consciência sanitária dos cidadãos de São Paulo. ${ }^{46}$

O intuito de criar uma consciência sanitária paulista, viabilizada por estratégias de educação sanitária associada aos modelos de atenção implantados nos inúmeros serviços, como delegacias e centros de saúde, a partir da primeira metade do século XX, se aliava à ideia de manter a mão de obra trabalhadora saudável para fins capitalistas. ${ }^{47}$

Os serviços de saúde começavam a ter sua funcionalidade e tradição contestadas, pois, a partir da primeira metade do século XX em São Paulo, já se propagava a concepção que tais serviços não deveriam se limitar à prestação de assistência médica individual para o público, mas também educá-los estabelecendo parâmetros de prevenção às doenças

\footnotetext{
44 Marques, Brasileiro e Fernandes, «Informação e disciplina».

45 Renovato e Bagnato, «A educação sanitária».

46 Lina Rodrigues de Faria, «A Fundação Rockefeller e os serviços de saúde em São Paulo (1920-30): perspectivas históricas», História, Ciências, Saúde - Manguinhos 9 (3), (2002): 561-590. https://doi.org/10.1590/S010459702002000300005.

47 Silva et al., «Educação em saúde».
} 
e criar assim a tão almejada consciência sanitária como percebe no excerto abaixo:

[...] os serviços que comprehendem não cabem inteiramente em divisóes estanques, inattingiveis pela finalidade commum dos resultados a collimar; prolongamento da accão do Estado em materia puramente clinica, sem objetivos sanitarios propriamente ditos, como se verifica com a simples assistencia medicamentosa, que não educa, que se abstráe da formação da consciência sanitaria e conduz a um circulo vicioso qual o da facilidade da cura gratuita, sem nenhum objectivo de alcance prophylactico, propiciadora, de certo modo, de resultados oppostos aos da actividade educativa, como si fosse possivel conceituar como meros accessorios os habitos de hygiene, elementos substanciaes do padrão de saúde. ${ }^{48}$

Nessa perspectiva de disseminar a consciência sanitária coletiva, além da institucionalização e estruturação da rede de atendimentos, era imperativo a condução das questões de natalidade e cuidados com as crianças, justificando, em nome da vida e controle sanitário, uma maior interferência no corpo social indicando quais eram os papéis da maternidade para reprodução da vida e sua importância para futuro da força de trabalho.

Como afirmaram Brasileiro et al., ${ }^{49}$ no projeto biopolítico de educação sanitária na primeira metade do século XX, a mãe deveria assumir o protagonismo e a integralidade do cuidado da criança, guiado por um aparato normativo e prescritivo representando a medicina pediátrica no seio do lar, consolidando-se como propagadora de um projeto formador de futuros cidadãos paulistas, bons e saudáveis.

Assim, inúmeros e potentes meios de divulgação de educação sanitária foram desenvolvidos e distribuídos em solo paulista, como por exemplo o Livro das Mãezinhas, um manual dirigido às mães paulistas,

\footnotetext{
48 Francisco Borges Vieira, «Eschema da organização sanitaria do Estado de São Paulo», Boletín de la Oficina Sanitária Panamericana 15 (1), (1936): 5-6. https://iris.paho.org/handle/10665.2/18187 (consultado el 23-09-2021).

49 Brasileiro et al., «O governo do estado de São Paulo».
} 
publicado entre 1937 e 1964, composto por oito edições e amplamente divulgado em solo paulista nos demais estados brasileiros. ${ }^{50}$

O supracitado livro, por sua vez, enquanto estratégia de educação sanitária, escrito pelo pediatra Wladimir Toledo Piza, foi constituído por conteúdos normativos e prescritivos, sustentados por uma narrativa persuasiva, que buscava impactar as leitoras mães para a construção de um padrão de maternidade, moldando assim os comportamentos maternos avalizados por conceitos científicos. ${ }^{51}$

Dessa forma, os profissionais, de educação sanitária e demais envolvidos, no intuito de disseminar conceitos de maneira inteligível e acessível às futuras e potenciais multiplicadoras das normas e regras almejadas, embasavam-se em recursos pedagógicos diversos, como manuais, panfletos, recursos fotográficos, ${ }^{52}$ entre outros.

Nessa direção da difusão de esquemas normativos chancelados por estratégias de educação sanitária e dirigidos à infância, Turner (1961), ${ }^{53}$ então consultor da Organização Mundial de Saúde, em artigo publicado no Boletín de la Oficina Sanitaria, apontava que o problema de preparar um professor em educação sanitária estava na questão central de ser ou não parte de seu trabalho compartilhar a manutenção e a melhoria da saúde das crianças, o que concorreria para melhorar a saúde da coletividade em geral. $\mathrm{O}$ autor reconhecia que, considerando todos os estudos daquele período, embora a responsabilidade maior da saúde dos alunos recaísse sobre os pais, parte importante desse trabalho incumbiria às escolas e às demais organizações de saúde pública.

Além disso, «os processos de ensino-aprendizagem estavam ainda intimamente relacionados com as doenças infecciosas, havendo, portanto, uma relação nítida de causa-efeito. Isto tornava o conteúdo de

\footnotetext{
50 Brasileiro et al., «O governo do estado de São Paulo».

51 Brasileiro et al., «O governo do estado de São Paulo».

52 Maria da Penha Costa Vasconcellos e Jaime Rodrigues, «A fotografia como instrumento do trabalho do higienista (São Paulo, primeira metade do século XX)», História, Ciências, Saúde-Manguinhos 13 (2), (2006): $477-491$. https://doi.org/10.1590/S0104-59702006000200014.

53 C. E. Turner, «Preparación del maestro en educación para la salud», Boletín de la Oficina Sanitaria Panamericana, (jun. 1961): 513-524.https://iris.paho.org/bitstream/handle/10665.2/15082/v50n6p513.pdf?sequence=1\&isAllowed=y (consultado el 23-09-2021).
} 
ensino, além de óbvio bastante desejável». ${ }^{54}$ Assim, ratificavam a legitimidade da ciência e seu o entendimento de domínio e normatização da vida individual e coletiva por meio da causalidade da higiene e discurso da educação sanitária.

A imposição desses preceitos de modulação "passiva» dos corpos, por ferramentas educativas, não foi um processo fácil, visto que havia tensões com o conhecimento de cultura local e popular. Desse modo, a participação comunitária na produção e compreensão do conhecimento científico criou um difusor adequado de exercício e controle.

Assim, as estratégias que surtiram efeito na normatização dos costumes e no disciplinamento dos corpos na primeira metade do século XX, tiveram que se reinventar pedagogicamente, alinhando-se a um caráter modernizante, mas ainda com a meta de remover permanências e obstáculos culturais e psicossociais às inovações sociais de controle às patologias, para manter o domínio estrutural do corpo coletivo social. ${ }^{55}$

A exemplificação desse regulamento do corpo pode ser observada na veiculação da conduta educacional sobre a alimentação e nutrição e comportamento das pessoas, veiculações essas realizadas através de manuais que compunham uma coletânea com 21 séries publicadas sobre educação sanitária, publicados entre 1939 a 1952, que disseminava através do seu conteúdo um conjunto de normas prescritivas comportamentais em saúde, direcionados à população alfabetizada e sobretudo à classe trabalhadora, já que acreditava que os ensinamentos difundidos seriam garantias para que atingissem e mantivessem as necessárias condições para eficiência produtiva daqueles corpos. ${ }^{56}$

A difusão de esquemas de normalidade difundidos pela educação sanitária produziu no imaginário social do estado de São Paulo a obrigatoriedade do "dever cívico», em que os cidadãos tinham de ser protagonistas e responsáveis e, no caso, penalizados por suas faltas e descuidos frente às «incontestáveis» normas «infalíveis» de padronização do hábito de vida, uma vez que a educação sanitária era a entendida como a

\footnotetext{
54 Candeias, «Evolução histórica da educação em saúde», 358.

55 Silva et al., «Educação em saúde».

56 Marques, Brasileiro e Fernandes, «Informação e disciplina».
} 
«melhor arma de combate de que poderia lançar mão a escola, com vistas a garantir a ampla difusão dos conhecimentos e a inculcação dos hábitos saudáveis, assegurando a formação da consciência sanitária, base da estabilidade e segurança da nação». ${ }^{57}$

O que se percebeu é que, uma vez, instaurada e obtido modulação comportamental, ainda que minimamente, atinente aos preceitos básicos da educação sanitária difundida, cabia em seguida emergir um modelo de responsabilização e terceirização dos problemas de saúde para a gestão individual da vida, pois naquele período «a institucionalização da educação sanitária, como componente das ações do Estado, na figura de Paula Souza, corroborou o enfoque individualizante dessas ações educativas, transferindo ao sujeito considerado ignorante, portanto sem consciência sanitária, a responsabilidade pelas suas mazelas e doenças». ${ }^{58}$

\section{CONCLUSÃO}

O desenvolvimento de uma pesquisa acerca da sistematização de conceitos que permearam a prática de educação sanitária paulista, como um exemplo do ocorrido no Brasil no período do estudo, retratando, a partir da historiografia desta prática, foi um desafio ancorado em três premissas.

A primeira é a aliança entre saúde e educação, sempre presente no campo da Saúde Pública e em seus projetos de intervenção social e sanitária ao longo do tempo. Entre outros exemplos, podemos citar a ocorrência da pandemia SARS-COV2, com início em 2019 e, no momento de escrita deste texto, ainda presente no mundo, e as iniciativas de controle e disseminação de atitudes na busca de moldar um hábito individual e coletivo frente a esta epidemia e, outras que podem ocorrer.

A segunda premissa, refere-se ao fato de que falar sobre educação sanitária e seus, conceitos e usos em tempos atuais, em que a negação da educação e conhecimento científico sanitário são cultuados por muitos, é também se posicionar politicamente. As concepções eugênicas e biopolíticas

\footnotetext{
57 Rocha, «A educação sanitária», 92.

58 Santos, «O Plano de Educação Higiênica», 64.
} 
verificadas nos estudos sobre a estratégia da educação sanitária no Brasil, com exemplo do estado de São Paulo, apontam a necessidade de buscar transparência nas ações de Saúde Pública frente a problemas de saúde decorrentes de uma formação social onde a desigualdade social e em saúde foram resultantes do projeto de desenvolvimento nacional e estadual.

A terceira, mais propriamente vinculada ao estudo desenvolvido, é a necessidade estudos históricos, que se dediquem ao tema, com necessárias reflexões e análise crítica no sentido de evitar debates pouco críticos sobre a prática da educação sanitária, muitas das vezes entendida como uma intervenção salvadora mística ou então, como uma intervenção controladora que reforça desigualdades através do seu poder pragmático, sem considerar movimentos sociais de resistência, ou mesmo de construção de estratégias singulares de saber frente à vida e a doença por parte de diferentes coletividades.

A educação sanitária, utilizada como prática de Saúde Pública sofisticada de transferência individual e coletiva para controle e resolução de situações de saúde na população, sem que um projeto de mudança social democrático duradouro fosse implementado, precisa ser reconhecida, no sentido de recolocar suas possibilidades como projeto emancipador de direito à saúde.

A afirmação acima confronta com os achados do presente estudo, em que a eugenia e o biopoder, foram consideradas características importantes para sustentação de um projeto de educação sanitária, que teve seu início nos primórdios do século XX. Como identificado entre os textos analisados, nota-se o quanto a medicina institucionalizada contribuiu a legitimou a introdução de novos hábitos e padrões de vida à população paulista, apoiada pela retórica do discurso científico e auxiliada pelas ferramentas e estratégicas de divulgações em massa. No período do início do século XX até meados da década de 1960, a educação sanitária incorporou influências eugênicas e da biolítica, para consolidar-se, não mais como uma ação sanitária, mas como uma política pública de saúde reconhecida.

Assim, a educação sanitária em São Paulo no período estudado se institucionalizou como política de saúde pública, tendo se capilarizado 
no pensamento social de saúde e também cultural, como ferramenta de transformação coletiva em um "estado moderno», caracterizada como uma potente «ferramenta de governamentalidade».

Importa mencionar, também, que disciplina e normatização, são fetiches de modelos de sociedades produtivistas, pragmáticas e que reforçam o molde capitalista de produzir e gerenciar vidas. A educação e a saúde, compreendidas como um direito social e humano, e aliadas em um projeto emancipador de cidadania, podem e devem fazer parte da proteção e atenção à população, como previsto na Constituição Brasileira de 1988. Neste projeto não cabem preceitos eugênicos, racismos, controle policial, cultura do higienismo, entre outros, sob riscos de retrocedermos a estratégias da educação sanitária do começo do século XX.

\section{Notas sobre os autores}

Maria Cristina da Costa Maroues é Professora Doutora do Departamento de Gestão, Política e Saúde, Faculdade de Saúde Pública, Universidade de São Paulo. Doutorado e Mestre em História Social pela USP. Possui Estágio de Formação em Demografia Histórica na Ecole des Hautes Etudes en Sciences Sociales/ Paris/França. Possui Experiência docente, ensino, pesquisa e cooperação técnica em saúde coletiva, história da saúde e ciências humanas em saúde, com interesse em políticas públicas, proteção à saúde com ênfase em vigilância e história social da saúde

Danilo Fernandes Brasileiro é Mestre em Ciências pela Universidade Federal de São Paulo (UNIFESP). Aluno de Doutorado da Faculdade de Saúde Pública da Universidade de São Paulo (FSP-USP). Atualmente é Enfermeiro, Servidor Público, do Hospital das Clínicas da Faculdade de Medicina da Universidade de São Paulo (HCFMUSP).

JoÃo de OliveIRa Gusmão é Estudante do Bacharelado de Saúde Pública da Faculdade de Saúde Pública da Universidade de São Paulo (FSP-USP). Atualmente é estagiário de saúde pública na Supervisão Técnica de Ermelino Matarazzo da Secretária Municipal de Saúde da Prefeitura Municipal de São Paulo (SMS/PMSP) com atuação vinculada ao planejamento em saúde, logística de vacinação, gestão da APS e indicadores de saúde. 


\section{REFERÊNCIAS}

Almeida, Fábio de Oliveira. «Reforma Sanitária e política paulista: as relações entre os processos de profissionalizações dos médicos de São Paulo e políticas de saúde do governo estadual Adhemar de Barros». Tesis de maestría, Universidade Federal de São Carlos, 2010.

Borges Vieira, Francisco. «Eschema da organização sanitaria do Estado de São Paulo». Boletín de la Oficina Sanitaria Panamericana 15, no. 1 (1936): 5-13. https://iris.paho.org/handle/10665.2/18187 (consultado el 23-09-2021).

Candeias, Nelly Martins Ferreira. «Evolução histórica da educação em saúde como disciplina de ensino na Faculdade de Saúde Pública da Universidade de São Paulo - 1925 a 1967». Revista de Saúde Pública 22, no. 4 (1988): 347365. https://doi.org/10.1590/S0034-89101988000400013.

Cont, Valdeir Del. «Francis Galton: eugenia e hereditariedade». Scientiae Studia 6, n. 2 (2008): 201-218. https://doi.org/10.1590/S1678-31662008000200004.

Duarte, Ivomar Gomes. «O código sanitário estadual de 1918 e a epidemia de gripe espanhola». Cadernos de História da Ciência 5, no. 1 (2009): 55-73. http:// periodicos.ses.sp.bvs.br/scielo.php?script=sci_arttext\&pid=S180976342 009000100004\&lng=pt\&nrm=iso (consultado el 23-09-2021).

Faria, Lina Rodrigues de. "A Fundação Rockefeller e os serviços de saúde em São Paulo (1920-30): perspectivas históricas». História, Ciências, Saúde Manguinhos 9, no. 3 (2002): 561-590. https://doi.org/10.1590/S0104-5970200 2000300005.

Fernandes, Rodrigo Contrera Ramos, Bianca Oliveira Ferro e Maria Cristina da Costa Marques. «O governo do estado de São Paulo se interessa pelo teu filho: o ideal de mãe em São Paulo de 1937 a 1964». História da Enfermagem 9, no. 1 (2018): 20-34. https://pesquisa.bvsalud.org/portal/resource/pt/biblio-948334 (consultado el 23-09-2021).

Foucault, Michel. Segurança, território, população: curso dado no Collège de France (1977-1978). São Paulo: Martins Fontes, 2008.

Furtado, Rafael Nogueira e Juliana Camilo Aparecida de Oliveira. «O conceito de biopoder no pensamento de Michel Foucault». Subjetividades 16, no. 3 (2016): 34-44. https://doi.org/10.5020/23590777.16.3.34-44.

Kobayashi, Elisabete, Lina Rodrigues de Faria e Maria Conceição Costa. «Eugenia e Fundação Rockefeller no Brasil: a saúde como proposta de regeneração nacional». Sociologias 11, no. 22 (2009): 314-351. https://doi.org/10. 1590/S1517-45222009000200012.

Mantovani, Rafael e Maria Cristina da Costa Marques. «Higiene como prática individual e como instrumento de Estado». História, Ciências, Saúde - Manguinhos 27, no. 2 (2020): 337-354. https://doi.org/10.1590/s0104-59702020 000200002 . 
Marques, Maria Cristina da Costa, Danilo Fernandes Brasileiro y Suzana César Gouveia Fernandes. «Informação e disciplina: a Coletânea de Educação Sanitária do estado de São Paulo, Brasil (1939-1952)». Interface 21, no. 61 (2017): 397-410. https://doi.org/10.1590/1807-57622016.0100.

Mascarenhas, Rodolfo Santos. «Contribuição para o estudo da administração estadual em São Paulo». Tesis de docencia libre, Faculdade de Higiene e Saúde Pública, Universidade de São Paulo, 1949.

Mello, Guilherme Arantes. «Pensamento clássico da saúde pública paulista na era dos centros de saúde e educação sanitária». Revista de Saúde Pública 46, no. 4 (2012): 751-758. https://doi.org/10.1590/S0034-89102012005000049.

Mello, Guilherme Arantes, Nelson Ibanez e Ana Luiza d'Ávila Viana. «Um olhar histórico sobre a questão regional e os serviços básicos de saúde no Estado de São Paulo». Saúde e Sociedade 20, no. 4 (2011): 853-866. https://doi. org/10.1590/S0104-12902011000400004.

Merhy, Emerson Elias. A saúde pública como política. São Paulo: Hucitec, 2006. Mota, André. «Higienizando a raça pelas mãos da educação ruralista: o caso do Grupo Escolar Rural do Butantan em 1930». Interface 14, no. 32 (2010): 9-22. https://doi.org/10.1590/S1414-32832010000100002.

Mota, André. "Quem tem medo da eugenia? Permanências discursivas de uma prática inacabada». En As doenças e os medos sociais, organizado por Monteiro, Yara Nogueira e Maria Luiza Tucci Carneiro, 219-249. São Paulo: Fap-Unifesp, 2012.

Mota, André, Lilia Blima Schraiber e José Ricardo de Carvalho Mesquita Ayres. "A Reforma Leser: a arquitetura de um projeto de saúde pública paulista, 1967-1979». Saúde e Sociedade 28, no. 4 (2019): 267-283. https://doi.org/10. 1590/s0104-12902019190043.

Reis, José Roberto Franco. "De pequenino é que se torce o pepino”: a infância nos programas eugênicos da Liga Brasileira de Higiene Mental». História, Ciências, Saúde - Manguinhos 7, no. 1 (2000): 135-157. https://doi.org/10.15 90/S0104-59702000000200007.

Renovato, Rogério Dias e Maria Helena Salgado Bagnato. "A educação sanitária nos Centros de Saúde de São Paulo (1925-1930): práticas e sujeitos». História da Enfermagem 2, no. 2 (2011): 61-72. https://pesquisa.bvsalud.org/ portal/resource/pt/biblio-1028940 (consultado el 23-09-2021).

Renovato, Rogério Dias e Maria Helena Salgado Bagnato. «Práticas educativas em saúde e a constituição de sujeitos ativos». Texto \& Contexto - Enfermagem 19, no. 3 (2009): 554-562. https://doi.org/10.1590/S0104-070720100003 00018.

Rocha, Heloísa Helena Pimenta. «A educação sanitária como profissão feminina». Cadernos Pagu 24 (2005): 69-104. https://doi.org/10.1590/S0104-83332 005000100005. 
Rodrigues, Jaime e Maria da Penha Costa Vasconcellos. «A guerra e as laranjas: uma palestra radiofônica sobre o valor alimentício das frutas nacionais (1940)». História, Ciências, Saúde-Manguinhos 14, no. 4 (2007): 1401-1414. https://doi.org/10.1590/S0104-59702007000400016.

Santos, Ricardo Augusto dos. "O Plano de Educação Higiênica de Belisário Penna. 1900-1930». Dynamis 32, no. 1 (2012): 45-68. https://doi.org/10.4321/ S0211-95362012000100003.

Silva, Cristiane Maria da Costa, Marcelo de Castro Meneghim, Antonio Carlos Pereira e Fábio Luiz Mialhe. «Educação em saúde: uma reflexão histórica de suas práticas». Ciência \& Saúde Coletiva 15, no. 5 (2010): 2539-2550. https://doi.org/10.1590/S1413-81232010000500028.

Soares, Márcia Guedes. "A Política de Educação do Serviço Sanitário de São Paulo entre a República Velha e o Estado Novo». Tesis de maestría, Faculdade de Educação, Universidade Estadual de Campinas, 2017.

Souza, Érica Mello de. «Educação sanitária: orientações e práticas federais desde o Serviço de Propaganda e Educação Sanitária ao Serviço Nacional de Educação Sanitária (1920-1940)». Tesis de maestría, Casa de Oswaldo Cruz, 2012.

Souza, Marcela Tavares de, Michelly Dias da Silva e Rachel de Carvalho. «Revisão integrativa: o que é e como fazer». Einstein 8, no. 1 (2010): 102-106. https://doi.org/10.1590/s1679-45082010rw1134.

Souza, Vanderlei Sebastião de. "Arthur Neiva e a "questão nacional" nos anos 1910 e 1920». História, Ciências, Saúde - Manguinhos 16, no. 1 (2009): 249264. https://doi.org/10.1590/S0104-59702009000500012.

Turner, C. E. «Preparación del maestro en educación para la salud». Boletín de la Oficina Sanitaria Panamericana, jun. (1961): 513-524. Documento WHO/ HEP/51, 22 oct. 1959.https://iris.paho.org/bitstream/handle/10665.2/15082/ v50n6p513.pdf? sequence=1 \&isAllowed =y (consultado el 23-09-2021)

Vasconcellos, Maria da Penha Costa e Jaime Rodrigues. «A fotografia como instrumento do trabalho do higienista (São Paulo, primeira metade do século XX)». História, Ciências, Saúde - Manguinhos 13, no. 2 (2006): 477-491. https://doi.org/10.1590/S0104-59702006000200014. 